\title{
Static Holdup of Liquid Slag in Carbonaceous Beds
}

\author{
Dongik JANG, ${ }^{1)}$ Minsoo SHIN, ${ }^{1)}$ Joon Seok $\mathrm{OH}_{,}{ }^{1)}$ Hyun-Soo $\mathrm{KIM}^{2)}$ Sang Ho $\mathrm{YI}^{2)}$ and Joonho LEE ${ }^{3) *}$ \\ 1) Graduate Student, Department of Materials Science and Engineering, Korea University, Anam-dong, Seongbuk-gu, Seoul, \\ 136-713, Republic of Korea. $\quad$ 2) Technical Research Laboratories, POSCO, Nam-Gu, Pohang, 790-785, Republic of Korea. \\ 3) Department of Materials Science and Engineering, Korea University, Anam-dong, Seongbuk-gu, Seoul, 136-713, Republic of \\ Korea.
}

(Received on November 1, 2013; accepted on January 9, 2014)

\begin{abstract}
The static holdup of liquid slag in carbonaceous beds at high temperatures was studied using lab-scale experiments. The effects of particle size, type of carbonaceous materials, and slag composition on the static holdup of liquid slag were investigated. The particle diameter was found to be the most important factor determining the static holdup. From the experimental results, the empirical dimensionless correlation for the static holdup of liquid slag $\left(H_{s}\right)$ in the carbonaceous beds was derived in terms of the modified capillary number $\left(C_{p m}\right)$.
\end{abstract}

$$
H_{S}=32.9 \times C_{p m}^{-0.562}
$$

KEY WORDS: capillary force; char; coke; carbonaceous bed; ironmaking; slag holdup.

\section{Introduction}

In the view of the global warming and depletion of natural resources, much effort has been directed toward environmentally-kindly iron-making process. For instance, in order to increase the energy efficiency of the blast furnace (BF), recently, the size of the BF has been increased. One of the largest BFs owned by POSCO at its Pohang steel works has a volume of $5600 \mathrm{~m}^{3}$. On the other hand, new iron-making processes such as FINEX, COREX, FASTMET, ITmk3, etc. have been developed to use lower grades of raw materials. High production efficiencies can be achieved in these processes when the counter flow of gas and molten slag and metal in a carbonaceous bed is controlled effectively. Excessive slag holdup in the carbonaceous bed may prevent continuous gas flow, yielding uneven temperature distribution in the carbonaceous bed. In addition, while the use of non-coking coal with and without cokes has been studied for many years, it is uncertain whether non-coking coals show different holdup properties in comparison to cokes.

Liquid holdup has been studied extensively for many years by many researchers. ${ }^{1-17)}$ Shulman et al. ${ }^{2)}$ suggested that the liquid holdup is composed of static and operating (dynamic) hold-up. Because of the difficulties encountered in high temperature experiments, many cold model studies have been widely carried out. ${ }^{1-12)}$ In the cold model studies, aqueous solutions and alumina or waxed spheres were generally used instead of liquid slags and carbonaceous materials, respectively. However, in the cold model studies, the

* Corresponding author: E-mail: joonholee@korea.ac.kr DOI: http://dx.doi.org/10.2355/isijinternational.54.1251 density of the liquid is smaller than the solid particles, whereas the density of the liquid slag in the BF operations is larger than the solid carbonaceous materials. In addition, the carbonaceous materials used in the BF operations generally show non-wetting behavior by liquid slag, whereas the solid particles used in the cold model studies show wetting behavior by aqueous solutions. Therefore, the cold model study is considered insufficient to predict the slag holdup behavior in the carbonaceous beds at high temperatures. Several researchers investigated the liquid slag holdup in a coke bed at high temperatures. ${ }^{13-17)}$ However, the experimental results obtained at high temperatures could not always be explained by the equations suggested by the cold model studies. Therefore, in order to understand the holdup of liquid slag in carbonaceous beds at high temperatures, high temperature experiments and relevant models are required.

In this study, lab-scale slag holdup experiments were carried out at high temperatures. Two kinds of carbonaceous beds (cokes and chars) were used. Based on the experimental results, a new slag holdup equation is suggested.

\section{Theory}

When the supply of liquid through a packed bed is the same as the drain, i.e., when the liquid flow through a packed bed is in a steady state, the volume fraction of the liquid in the packed bed is called liquid holdup. Liquid holdup $\left(H_{t}\right)$ is composed of static $\left(H_{s}\right)$ and dynamic $\left(H_{d}\right)$ holdups. ${ }^{3)}$ Static holdup is the volume fraction of the liquid in the packed bed, which remains in the bed when the supply of liquid is stopped. Dynamic holdup is the volume fraction of the liquid in the bed, which drains out from the bed when 
the supply of liquid is stopped.

$$
H_{t}=H_{s}+H_{d}
$$

Kawabata et al. reported that when there is no gas injection from the bottom, the static holdup, which is much larger than the dynamic holdup, is a dominant factor determining the total holdup. ${ }^{8,9)}$ Moreover, when the static and dynamic holdups are investigated simultaneously, the reliability of the obtained results becomes lower. ${ }^{14-16)}$ Therefore, in this study, only the static holdup is considered.

Static holdup is determined by the balance between the gravitational force and the solid-liquid wetting force. A dimensionless number is defined as the modified capillary number $\left(C_{p m}\right)^{3)}$ as per Eq. (2).

$$
C_{p m}=\frac{\rho_{L} \cdot g \cdot \phi^{2} \cdot D_{p}^{2}}{\sigma_{L} \cdot(1+\cos \theta) \cdot(1-\varepsilon)^{2}}
$$

In the above equation, $\rho_{L}, g, \phi, D_{p}, \sigma_{L}, \theta$, and $\varepsilon$ denote the density of liquid, gravitational acceleration, shape factor, particle size, surface tension of the liquid, contact angle between the liquid and a solid particle, and void fraction, respectively.

It is generally accepted that the static holdup is described as a function of $C_{p m}$. Table 1 summarizes the reported equations. All the equations can be expressed by two types of equations, Eqs. (3) and (4), as follows:

$$
\begin{gathered}
H_{s}(\%)=\frac{100}{a+b \cdot C_{p m}^{n}} \\
H_{s}(\%)=c \cdot C_{p m}^{n} \ldots
\end{gathered}
$$

In the above equations, $a, b, c$, and $n$ are empirical constants, which are determined from the best fit of the experimental data. Both equations suggest that the static holdup decreases with increasing $C_{p m}$.

In Fig. 1, the static holdup equations are plotted with respect to $C_{p m}$. For comparison, data reported by Niwa et $a l .{ }^{13)}$ from BF sampling and data from the high temperature experiments carried out by Husslage et al. ${ }^{15)}$ are plotted together. The BF sampling data by Niwa et al. ${ }^{13)}$ showed reasonable agreements with the predicted values, while the high temperature experimental measurements by Husslage et $a l .{ }^{15)}$ were much higher than the predicted values. Hence, the current model determined by cold model studies is unsuitable to predict the slag holdup behavior in carbonaceous beds.

\section{Experimental}

Figure 2 shows a schematic illustration of the experimental apparatus. A graphite crucible (I.D $=55 \mathrm{~mm}$, height $=75 \mathrm{~mm}$ ) consisting of 33 holes (each of diameter $=$ $5 \mathrm{~mm}$ ) on the bottom was used. In the graphite crucible, coke or char particles were charged to form a carbonaceous bed. The compositions of coke and char are shown in Table 2. The coke particles were distributed in four groups (4-5, $8-9,14-15$, and $20-24 \mathrm{~mm}$ ). The number of coke particles placed in each layer was $103,28,9$, and 4 , respectively. In the experiments, $16,8,5$, and 4 layers of coke were charged

Table 1. Equations describing the static holdup as a function of the modified capillary number.

\begin{tabular}{ccc}
\hline Researcher & Static holdup $(\%)$ & Ref. \\
\hline Fukutake and Rajakumar & $100 /\left(20.5+0.263 \cdot \mathrm{C}_{\mathrm{pm}}\right)$ & $3)$ \\
Chew et al. & $100 /\left(21+0.305 \cdot \mathrm{C}_{\mathrm{pm}}\right)$ & $7)$ \\
Kawabata et al. & $100 /\left(26+0.27 \cdot \mathrm{C}_{\mathrm{pm}}{ }^{0.9}\right)$ & $9)$ \\
\hline
\end{tabular}

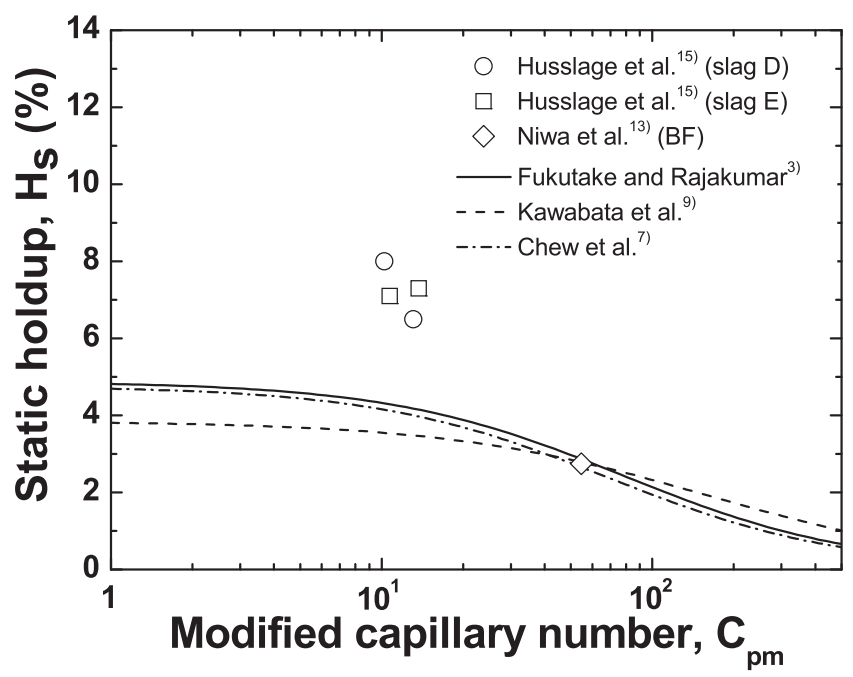

Fig. 1. Static holdup as a function of the modified capillary number.

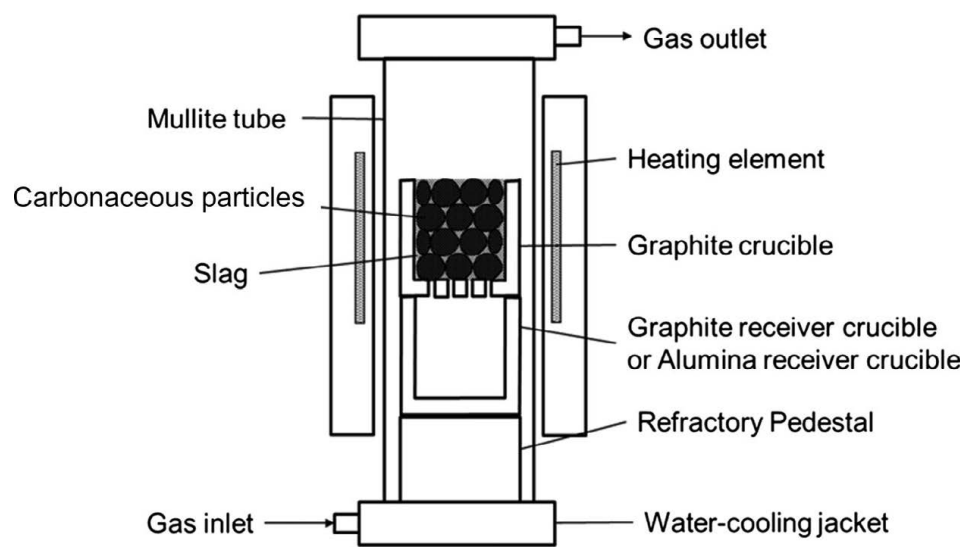

Fig. 2. Experimental setup used for evaluating the static holdup. 
in the crucible. The height of the packed bed ranged from $25 \mathrm{~mm}$ to $75 \mathrm{~mm}$. Two groups of char particles (8-9 and 14$15 \mathrm{~mm}$ ) were used. The number of chars per layer was the same as that of the number of cokes per layer. Then, fine slag particles were filled in the space among the carbonaceous beds. The slag composition is shown in Table 3. The graphite crucible containing the carbonaceous materials and slag particles was placed in a mullite reaction tube (I.D = $92 \mathrm{~mm}$, height $=900 \mathrm{~mm}$ ). Under the graphite crucible, a slag receiver of the same size as that of the graphite crucible was placed. The sample assembly was heated in an Ar atmosphere to $1723 \mathrm{~K}$ at a heating rate of $+8.3 \mathrm{~K} / \mathrm{min}$. The temperature was held at $1723 \mathrm{~K}$ for $90 \mathrm{~min}$ and the sample was cooled down to room temperature at a cooling rate of $-8.3 \mathrm{~K} / \mathrm{min}$. When the slag was molten, it dropped into the receiver through the carbonaceous bed. After the experiment, the amounts of slag remaining in the carbonaceous bed and that drained into the slag receiver were measured. The experiments were repeated 4-5 times with the carbonaceous particles of the same size. In addition, the top surface and the cross section of the carbonaceous beds were investigated after the experiments. The shape factor of the

Table 2. Composition of the cokes and chars used in the present experiments $(w t \%)$.

\begin{tabular}{ccccc}
\hline Component & Moisture & Volatile Matter & Ash & Fixed Carbon \\
\hline Coke & 0.22 & 1.76 & 11.66 & 86.36 \\
Char & 2.71 & 4.71 & 17.11 & 75.47 \\
\hline
\end{tabular}

Table 3. Chemical composition of the slag (wt\%).

\begin{tabular}{ccccccc}
\hline & $\mathrm{Al}_{2} \mathrm{O}_{3}$ & $\mathrm{CaO}$ & $\mathrm{MgO}$ & $\mathrm{SiO}_{2}$ & $\mathrm{FeO}$ & Ref. \\
\hline Slag A & 18 & 40 & 10 & 32 & & $\begin{array}{c}\text { Present } \\
\text { Work }\end{array}$ \\
Slag B & 16 & 44.5 & 4 & 35.5 & & \\
Slag C & 14.4 & 32 & 8 & 25.6 & 20 & $13)$ \\
Slag D & 10 & 38 & 12 & 40 & & $15)$ \\
Slag E & 12 & 43 & 13 & 32 & & $15)$ \\
\hline
\end{tabular}

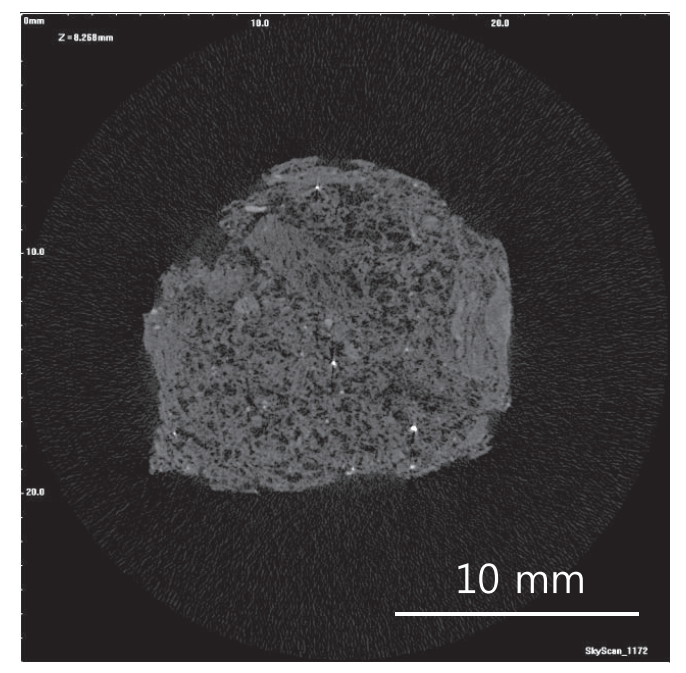

Fig. 3. Typical scanned cross-sectional CT image of a coke particle. carbonaceous particles was estimated using a high resolution micro-CT (Syscan1172, Bruker Corporation). A typical cross-sectional image of a scanned particle is shown in Fig. 3.

\section{Results and Discussion}

Figure 4 shows the photos of the top-surface and the cross-section of the coke beds after experimentation with slag A. In the bed with coke particles of 4-5 $\mathrm{mm}$ in diameter, most of slag was placed on the top of the coke bed. Slag was absent in the slag receiver. We assumed that the liquid slag formed on the top surface soaked the liquid slag within the coke bed owing to capillary forces. In the bed with coke particles of 8-9 mm diameter, slag droplets were observed between the coke particles. In the bed with coke particles of 14-15 and 20-24 mm particles, slag was found on the surface of coke particles. Several researchers have pointed out that channeling of liquid flow may occur in a relatively large scale packed bed. ${ }^{8,9,11)}$ However, in the lab-scale high temperature experiments, the experimental system was not large enough to identify the channeling effect. Therefore, it is more realistic to consider the static holdup without taking into account the channeling effect.

In Fig. 5, the effect of the particle size of the cokes on the static holdup is shown with respect to $C_{p m}$. Since the two slags under examination showed no considerable differences, all the data were plotted together. $C_{p m}$ was calculated from Eq. (2). The density and surface tension were obtained from Ref. 18). The contact angle was separately investigated. ${ }^{19)}$ The void fraction was calculated using Eq. (5).

$$
\varepsilon=1-\frac{\left(W_{c} / \rho_{a p p}\right)}{V_{t}}
$$

In the above equation, $V_{t}$ is the total volume of the packed bed, $W_{c}$ is the total weight of the carbonaceous particles in the crucible, and $\rho_{a p p}$ is the apparent density of the carbonaceous particles. All the thermophysical data used in the present study are summarized in Table 4. The mean static holdups of slag A in the coke bed consisting of particles with diameters of 8-9, 14-15, and 20-24 $\mathrm{mm}$ were 8.55 , 3.65 , and $3.68 \%$, respectively. However, the slag did not flow through the packed coke bed consisting of particles of diameter 4-5 mm (Fig. 4(a)). The measurements were reproducible with the same particle diameter. The maximum difference in the measured static holdup was $24 \%$. These differences were caused by the packed structure and the low height of the coke bed.

Static holdup is generally accepted as a function of a dimensionless modified capillary number as shown in Eq. (6) or (7).

$$
\begin{gathered}
H_{s}(\%)=\frac{100}{7.195+0.415 \cdot C_{p m}} \\
H_{s}(\%)=32.9 \cdot C_{p m}^{-0.562} \ldots .
\end{gathered}
$$

The values predicted with Eqs. (6) and (7) reasonably agreed with the data reported by Niwa et al. ${ }^{13)}$ and Husslage et al. ${ }^{14)}$ However, Eq. (6) (dashed line in Fig. 5) was found to be unsuitable for the prediction of the slag holdup, 

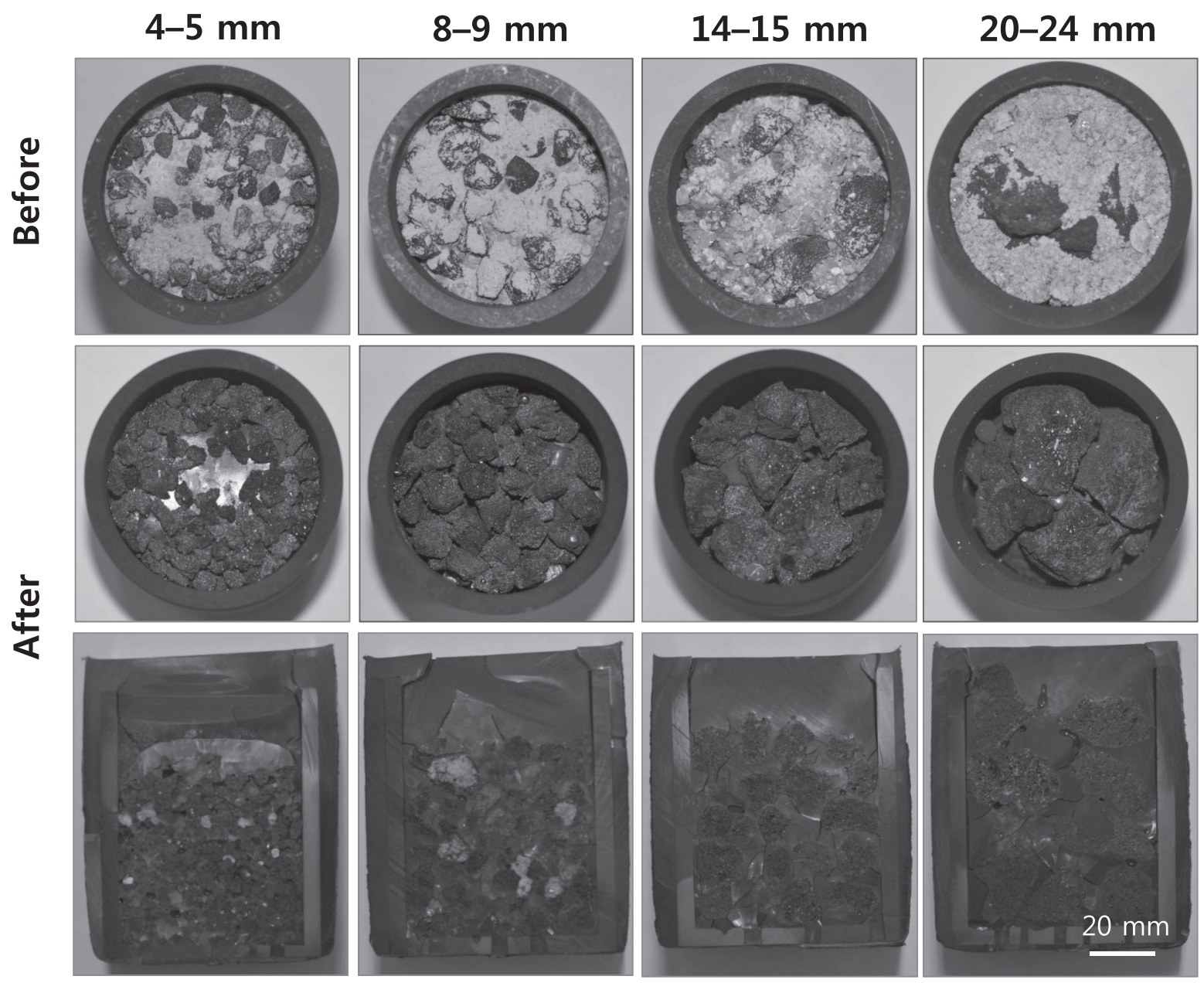

Fig. 4. Coke beds before and after the static holdup experiments.

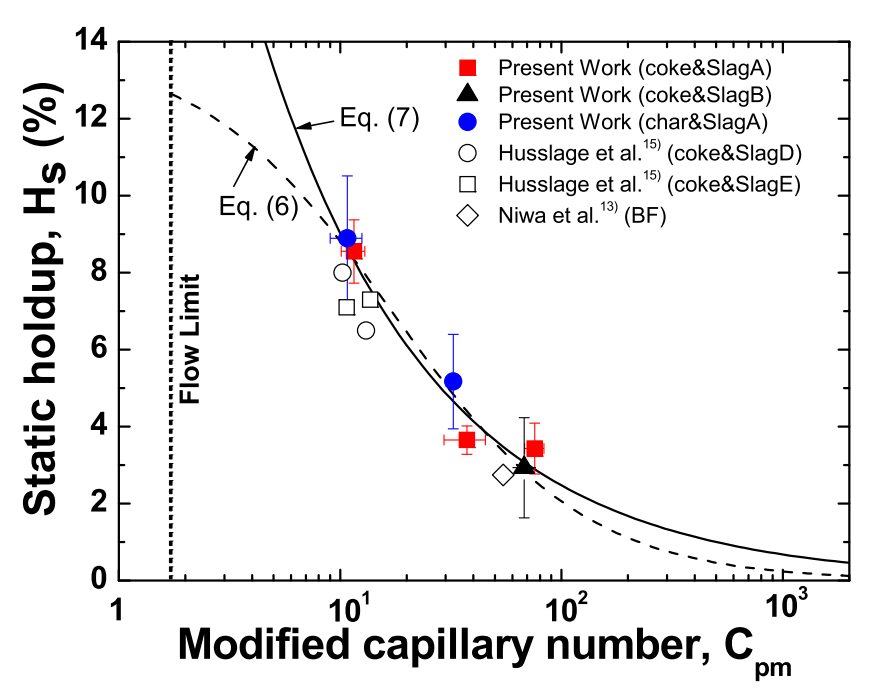

Fig. 5. Static holdup as a function of the modified capillary number. (Online version in color.)

because it cannot explain the present experimental results with coke particles of 4-5 $\mathrm{mm}$ in diameter. However, Eq. (7) is more suitable for the prediction of the slag holdup (solid line in Fig. 5). The mean static holdups of slag B in the coke bed consisting of particles with diameters of 14-15 and 20$24 \mathrm{~mm}$ were 3.33 and $2.93 \%$, respectively. The data obtained with slag B agreed well with the values predicted with Eq. (7).
Table 4. Thermophysical properties used for the calculation of the modified capillary number.

\begin{tabular}{ccc}
\hline & Slag A & Slag B \\
\hline Density $\left(\mathrm{kg} / \mathrm{m}^{3}\right)^{18)}$ & 2773 & 2766 \\
Surface tension $\left(\mathrm{N} / \mathrm{m}^{18)}\right.$ & 0.485 & 0.480 \\
Contact angle with coke $\left({ }^{\circ}\right)^{19)}$ & 118 & 122 \\
Contact angle with char $\left({ }^{\circ}\right)^{19)}$ & 122 & - \\
Void fraction $(-)$ & $0.46-0.58$ & $0.47-0.49$ \\
Apparent density $\left(\mathrm{kg} / \mathrm{m}^{3}\right)$ & Coke & Char \\
Shape factor $(-)$ & 921 & 950 \\
\hline
\end{tabular}

It is noteworthy that the values obtained with Eq. (7) from the high temperature experiments agreed well with the values predicted using the cold model experiments when $C_{p m}$ was larger than 20. However, the hot model data became much larger than the cold model predictions when $C_{p m}$ was smaller than 20 . In the cold model studies, as addressed before, the density of the liquid is smaller than that of the solid particles; however, the density of liquid slag is larger than that of the solid carbonaceous materials. In addition, the solid particles used in the cold model studies are wetted by aqueous solutions, while the carbonaceous 
materials used in the high temperature experiments are not wetted by liquid slag. Accordingly, when the slag between the carbonaceous particles is molten, it may push the nearby particles and provide larger room. This tendency becomes stronger as the capillary forces increase by decreasing the gap between the particles. Consequently, as the particle size decreases, the static holdup increases more rapidly.

In Fig. 5, the static holdup of slag $A$ in the char bed is shown together. The mean static holdups for particles with diameters of $8-9$ and $14-15 \mathrm{~mm}$ were 8.89 and $5.17 \%$, respectively. The maximum difference in the measured static holdup was $34 \%$. Due to irregularity in the shape of the char particles, the experimental scatter was slightly larger than that observed for coke beds. All the thermophysical data used in the present study is summarized in Table 4. Differences in the thermophysical properties were found in the contact angle and the shape factor. The contact angle between char and liquid slag A was $122^{\circ}$ and the shape factor of the char particles was 0.52 . From Fig. 5, Eq. (7) was found to predict the experimental data with char beds as well. Hence, Eq. (7) seems suitable to predict the static holdup of liquid slag in coke and char beds examined in the present study.

\section{Conclusions}

The static holdup of liquid slag in carbonaceous beds at high temperatures was studied using lab-scale experiments. The effects of particle size, type of carbonaceous materials, and slag composition on the static holdup were investigated. The particle diameter was found to be the most important factor determining the static holdup. From the experimental results, an empirical dimensionless correlation for the static holdup of liquid slag in the carbonaceous beds was derived in terms of the modified capillary number as $H_{s}(\%)=$ $32.9 \cdot C_{p m}^{-0.562}$.

\section{Acknowledgements}

This study was supported by a grant from POSCO. The authors would like to thank Mr. H. Kawabata and Prof. T. Usui of Osaka University for their constructive discussions and providing valuable references.

\section{REFERENCES}

1) P. C. Carman: Trans. Inst. Chem. Eng., 15 (1937), 150.

2) H. L. Shulman, C. F. Ullrich and N. Wells: AIChE J., 1 (1955), 247.

3) T. Fukutake and V. Rajakumar: Tetsu-to-Hagané, 66 (1980), 1937.

4) T. Sugiyama, T. Nakagawa, H. Sibaike and Y. Oda: Tetsu-to-Hagané, 73 (1987), 2044.

5) T. Usui, H. Kawabata, T. Sogo, S. Morii, M. Ichida and Z.-I. Morita: Tetsu-to- Hagané, 82 (1996), 899.

6) S. J. Chew, G. X. Wang, A. B. Yu and P. Zulli: Ironmaking Steelmaking, 24 (1997), 392.

7) S. J. Chew, P. Zulli and A. B. Yu: ISIJ Int., 41 (2001), 1112.

8) H. Kawabata, Z. Liu, F. Fujita and T. Usui: ISIJ Int., 45 (2005), 1466.

9) H. Kawabata, K. Shinmyou, T. Harada and T. Usui: ISIJ Int., 45 (2005), 1474.

10) K. Saito, K.-I. Ohno, T. Miki, Y. Sasaki and M. Hino: ISIJ Int., 46 (2006), 1783.

11) G. S. Gupta and K. Naveen: Metall. Mater. Trans. B, 38 (2007), 203.

12) Y. Bando, S. Hayashi, A. Matsubara and M. Nakamura: ISIJ Int., 45 (2005), 1461.

13) Y. Niwa, T. Sumigama, A. Maki, S. Nagano, A. Sakai and M. Sakurai: Tetsu-to-Hagané, 76 (1990), 337.

14) H. Ohgusu, Y. Sassa, Y. Tomita, K. Tanaka and M. Hasegawa: Tetsuto-Hagané, 78 (1992), 1164.

15) W. M. Husslage, M. A. Reuter, R. H. Heerema, T. Bakker and A. G. S. Steeghs: Metall. Mater. Trans. B, 36 (2005), 765.

16) W. M. Husslage: Doctoral Thesis, Delft University of Technology, Netherlands, (2004).

17) H. L. George, B. J. Monaghan, R. J. Longbottom, S. J. Chew and P. R. Austin: ISIJ Int., 53 (2013), 1172.

18) Verein Deutscher Eisenhuttenleute: Slag Atlas, 2nd ed., Verlag Stahleisen GmbH, Dusseldorf, (1995), 313, 403.

19) D. Jang: Master Thesis, Korea University, Seoul, Korea, (2013). 